\title{
O PAPEL ESTRATÉGICO DO CAPITAL HUMANO NA GESTÃO DE CRISE - A PANDEMIA DE COVID-19
}

\author{
THE STRATEGIC ROLE OF HUMAN CAPITAL IN CRISIS MANAGEMENT - THE COVID-19 \\ PANDEMIC
}

Carla Diniz dos Santos da Silva Mestre em Administração Ibmec RJ

Rio de Janeiro, RJ - Brasil. carla.diniz@icloud.com

Ana Beatriz Gomes de Mello Moraes Doutora em Gestão da Inovação e Tecnologia Ibmec RJ. Rio de Janeiro, RJ - Brasil. ana.moraes@ibmec.edu.br

\begin{abstract}
Resumo
Uma crise mundial foi instaurada quando a Organização Mundial da Saúde (OMS) declarou a Covid-19 como pandemia. Os executivos de uma transportadora de gás natural por gasodutos deveriam implementar um plano de gestão de crise para lidar com a situação. O presente relato técnico tem como objetivo descrever as etapas adotadas na gestão da crise da pandemia de Covid-19 numa empresa de transporte de gás natural por gasodutos, apresentando os desafios enfrentados na análise do cenário, a tomada de decisões em meio à incerteza do momento e os impactos das decisões tomadas sobre o planejamento estratégico da empresa e seus trabalhadores. A participação direta de uma das autoras no comitê de crise instaurado permitiu a produção do relato técnico conforme protocolo de Rojo (2014) segundo o método de estudo de caso. Os resultados obtidos passaram pela decisão de operar remotamente, com $100 \%$ dos empregados em teletrabalho. Nenhuma interrupção no serviço de transporte de gás natural foi registrada no período. Foram registrados quatro casos de contaminação dentre os 175 funcionários da empresa entre março e junho de 2020, bem como quatro casos de contaminação dentre 149 dependentes diretos. Nenhum funcionário ou seu dependente precisou ser internado para tratamento e nenhum óbito foi registrado. E as ações estratégicas previstas para o ano foram mantidas e realizadas.
\end{abstract}

Palavras-chave: Gestão de crise. Gestão de pessoas. Capital humano. Estratégia.

\begin{abstract}
A world crisis was started when the World Health Organization (WHO) declared Covid-19 a pandemic. Executives at a natural gas pipeline carrier should implement a crisis management plan to deal with the situation. The present technical report aims to describe the steps taken in the management of the Covid-19 pandemic crisis in a gas pipeline transportation company, presenting the challenges faced in analyzing the scenario, making decisions amid the uncertainty of the moment and the impacts of decisions made on the strategic planning of the company and its workers. The direct participation of one of the authors in the crisis committee established allowed the production of the technical report according to Rojo's protocol (2014) according to the case study method. The results obtained with the proposed intervention went through the decision to operate remotely, with $100 \%$ of employees working from home. No interruption in the natural gas transportation service was recorded in the period. There were 4 cases of contamination among the 175 employees of the Company between March and June 2020, as well as 4 cases of contamination among 149 direct dependents. Neither an employee nor his dependent needed to be hospitalized for treatment and not one death was recorded. And the strategic actions planned for the year were maintained and carried out.
\end{abstract}

Keywords: Crisis management. People management. Human capital. Strategy.

\section{Cite como}

American Psychological Association (APA)

Silva, C. D. S., \& Moraes, A. B. G. M. (2021, maio/ago.). O papel estratégico do capital humano na gestão de crise - a Pandemia de COVID-19. Revista de Gestão e Projetos (GeP), 12(2), 214-232. https://doi.org/10.5585/gep.v12i2.19255. 


\section{Introdução}

Uma crise mundial foi instaurada em março de 2020, quando a Organização Mundial da Saúde (OMS) declarou a Covid-19 como pandemia. Naquele momento, aqui no Brasil, ainda não se tinha noção do impacto que viria nas esferas social e econômica. Era o momento de as empresas brasileiras tomarem decisões sobre o planejamento estratégico que haviam acabado de aprovar para o ano e começarem a avaliar a implantação de comitês de crise que definiriam os próximos passos para proteger os negócios e seus empregados. Ainda que, naquele instante, parecesse ser uma situação que geraria apenas uma crise de saúde, já era possível imaginar o seu efeito econômico e social.

Como uma transportadora de gás natural por sistemas de gasodutos e com o registro recente de ocorrências de rompimento de dutos em instalações internacionais, a Nova Transportadora do Sudeste (NTS) tinha um plano de gestão de crise. Ademais, tinha também avaliado os potenciais riscos do negócio e elaborado planos de mitigação para os mais críticos. Um plano de continuidade de negócios estava igualmente implementado e testado, para evitar que qualquer situação deixasse a empresa paralisada.

Com o estabelecimento dessa crise, os executivos da NTS precisariam decidir como proteger os empregados e os negócios. E, também, avaliar no planejamento estratégico da empresa quais iniciativas deveriam seguir, quais priorizar e quais abandonar. A empresa estava há um ano da sua principal ação estratégica: a primarização das atividades de operação, até então terceirizadas. Essa ação havia sido planejada um ano antes e muito investimento já havia sido feito até ali. O cenário à frente era incerto. Até quando duraria a pandemia? Qual seria o seu efeito na economia? Qual seria o seu impacto social e nas relações de trabalho? Nenhuma dessas perguntas tinha resposta.

O trabalho está estruturado conforme o protocolo de relato técnico de Rojo (2014) e tem como objetivo descrever as etapas adotadas na gestão de crise da pandemia de Covid-19, especialmente no que tange a tomada de ações para mitigar o impacto sobre a empresa e seus trabalhadores. Tal estudo é relevante para lançar luz sobre o papel da área de recursos humanos durante e após uma crise (Vandalier, 2016), sendo essa abordagem escassa na literatura sobre gestão de crise (Myer, Conte \& Peterson, 2007). O método utilizado é o estudo de caso (Yin, 2015), sendo uma das autoras participante ativa do comitê de crise instaurado. O relato está estruturado apresentando as seguintes sessões: referencial teórico; contexto investigado; diagnóstico da situação-problema; intervenção proposta; resultados obtidos; e cntribuição tecnológico-social.

\section{Referencial teórico}

O referencial teórico destacado nesse tópico aborda os principais conceitos presentes na gestão de crise e seus impacto no capital 
humano, com o objetivo de suportar a compreen-são da situação-problema e a intervenção realizada (Rojo, 2014). A questão estratégica em si é um tópico de análise extensa e por esse motivo permeará apenas o contexto em que se encon-trava a empresa no momento da ocorrência da crise.

\subsection{A gestão de crise}

De acordo com Hermann (1972), uma crise pode ser caracterizada e distinguida de uma situação complexa por três elementos: a surpresa, a ameaça que traz em seu bojo e o curto tempo de resposta. Uma crise também pode ser descrita, conforme Vardarlier (2016), como um evento totalmente disruptivo ou parcialmente disruptivo para pessoas, propriedades, equipamentos ou meio ambiente e que pode terminar afetando negativamente o valor de uma empresa e sua reputação, frustrando a percepção das partes relacionadas sobre a organização. Dado o contexto atual, que permite o rápido alastramento dos efeitos dessas situações emergenciais de grande porte, é importante considerar o que Boin (2019) chama de "crises transfronteiras". Nesse cenário, observam-se o caráter de emergência das ações em todas as esferas e a falta dessas ações como um perigo para as sociedades. De mais a mais, Christensen, Lægreid e Rykkja (2016) acrescentam a necessidade de críticas e de debate aos elementos que, tradicionalmente, integram uma crise.

Os estudos sobre crises, na maioria das vezes, possuem um viés mais operacional e discutem tecnicamente procedimentos que apoiem o retorno à normalidade (Schmidt \& Mello, 2020). A gestão de crise é definida por Lockwood (2005) como atividades preestabelecidas e protocolos para preparar e responder a eventos ou incidentes catastróficos significativos de forma segura e efetiva. E ela incorpora, segundo a autora, programas organizacionais, como resposta à emergência, recuperação de desastres, gestão de riscos, plano de continuidade de negócios, plano de comunicação e outros.

De forma geral, as organizações procuram estar preparadas para alguns contextos de crise, mas, quase sempre, descobrem que não estão tão bem estruturadas quando se deparam, de fato, com os problemas impostos por desafios maiores do que os imaginados inicialmente (Boin, 2019). Esse cenário é o que se percebe também quando as nações se defrontam com uma pandemia, por exemplo. Desse modo, Christensen et al. (2016) observam que as causas de uma crise, o curso de ações escolhidas para lidar com ela e as consequências de cada escolha podem ser tanto incertas quanto complexas, por mais que seja imperativa uma ação rápida.

Com frequência, a questão do gerenciamento de crises é abordada por pesquisadores na esfera pública. Christensen $e t$ $a l$. (2016) chamam a atenção de que não se trata apenas de conteúdo técnico e apoio logístico, mas que envolve conflitos, que se desdobrarão em gerir a capacidade de governança e legitimidade das instituições. As empresas, por 
sua vez, não ficam à parte dos desafios enfrentados. De acordo com Kim e Lim (2020), gestores e empregados passam pelo processo de gestão da crise, porém o que poderá separá-los é a comunicação. Para os autores, a comunicação tem um papel importante para que a incerteza possa ser vencida, além disso, é importante que a empresa não só tenha ações de cuidado com as suas equipes, como também deixe caminhos abertos para ouvir as pessoas. A comunicação é parte extremamente relevante de uma crise para as diversas partes envolvidas no processo (Coombs, 2000).

\subsection{O capital humano e a gestão de crise}

O capital humano é reconhecido como uma fonte de geração de vantagem competitiva, bem como a gestão de Recursos Humanos é entendida como desenvolvedora de capacidades distintivas, que trarão vantagem competitiva à firma (Penrose, 1959; Wright, Dunford \& Snell, 2001; Wright, McMahan \& Mcwilliams, 1994). A criação de vantagem competitiva pode ocorrer quando uma organização consegue se adaptar rapidamente e até mesmo antever situações externas, que por seu turno fogem de seu controle (Penrose, 1959; Teece, Pisano \& Shuen, 1997).

O investimento em ativos intangíveis, como a cultura de organização e a reputação que é construída no relacionamento com partes interessadas e envolvidas em uma crise, por exemplo, comunidades ou empregados, pode ser um recurso estratégico capaz de impactar o valor de mercado de uma empresa
(Albuquerque, Koskinen, Yang, \& Zhang, 2020; Edmans, 2011; Ng, Yam \& Aguinis, 2019; Shan \& Tang, 2020). É papel da alta liderança considerar os impactos sociais, ambientais e de governança envolvidos em uma crise, posto que os investidores esperam a demonstração de resiliência e a construção de credibilidade durante períodos como esse ('t Hart \& Kouzmin, 1993; Cheema-Fox, LaPerla, Serafeim, \& Wang, 2020; Christensen et al., 2016; Coulson-Thomas, 2019).

Segundo Nathan (2000), uma crise pode ser enxergada como uma oportunidade ou uma ameaça. $\mathrm{E}$ a forma como se reage à crise irá definir o futuro da organização. A flexibilidade e a adaptação, evitando o vício da rigidez e a manutenção de um único caminho estratégico, poderão ser grandes fontes de criação de novas vantagens competitivas (Nathan, 2000; Teece et al., 1997).

Embora a maior parte dos artigos que tratam de resposta à crise considere a preparação do ambiente de TI e dos aspectos operacionais e logísticos envolvidos em uma crise (Spremic, Bajgorić \& Turulja, 2013), após o acidente de 11 de setembro de 2001, muitos passaram a olhar para o papel do capital humano antes, durante e após uma crise (Lockwood, 2005; Myer, Conte \& Peterson, 2007; Vardarlıer, 2016). Um conjunto de práticas foi adotado durante a pandemia de Covid-19, servindo como referência para as áreas de Recursos Humanos (Fri, 2020; Koirala \& Acharya, 2020). Além disso, alguns artigos descrevem o papel do RH em um de comitê de 
crise (Lockwood, 2005; Myer et al., 2007; Robinson, 2005), o que serviu como referência para a elaboração de ações no trabalho descrito nesse relato técnico.

\section{Contexto investigado}

Este relato técnico foi elaborado conforme protocolo de Rojo (2014). A metodologia utilizada foi de estudo de caso (Yin, 2015), avaliando em tempo real a intervenção realizada na Nova Transportadora do Sudeste em face da crise de Covid-19. Os dados coletados foram de fonte primária, com a participação direta de uma das autoras no comitê de crise instaurado na empresa, e fontes secundárias, como website da empresa e site da agência regulatória (ANP, 2019). Os dados primários e secundários foram coletados de março a junho de 2020.

\subsection{Caracterização da empresa}

Na década de 1980, foram descobertas as primeiras reservas de gás natural na bacia de Campos, no litoral do estado do Rio de Janeiro. Essa proximidade dos grandes centros de consumo permitiu que o insumo fosse integrado à matriz energética do país, correspondendo hoje a $12 \%$ da oferta interna de energia (Santos, 2000). Em 2003, foram iniciadas as construções por uma empresa estatal do sistema de gasodutos interligados no Brasil e as obras foram concluídas em 2006.

Em 2017, no primeiro movimento para a abertura do mercado de gás natural no país, a NTS, que era composta pela malha de gasodutos da região sudeste do Brasil, foi vendida para um grupo de investidores privados. A empresa detém contratos de concessão para operar $2048 \mathrm{~km}$ de gasodutos, atendendo os estados do Rio de Janeiro, São Paulo e Minas Gerais, regiões que concentram $69 \%$ do consumo de gás natural do país (Agência Nacional de Petróleo [ANP], 2019). Esses gasodutos escoam a produção do Rio de Janeiro e de Santos, no litoral Paulista, e se conectam com o gasoduto Bolívia-Brasil e à malha nordeste de gasodutos, vendida em 2019 para um outro consórcio de investidores privados.

\subsection{Caracterização do projeto}

A estratégia definida a partir da compra do ativo previa que todas as atividades inerentes a empresa fossem estabelecidas, isso porque a compra da empresa incluiu apenas os ativos físicos, nesse caso, os contratos de concessão dos gasodutos. Não viriam as pessoas, processos, sistemas, enfim, toda a estrutura de capital humano, organizacional e social precisaria ser construída do zero.

Uma vez que os serviços de transporte de gás natural precisariam continuar a ser atendidos durante a transição entre empresas, foram feitos dois tipos de contratos com a empresa vendedora: o primeiro, que suportaria as atividades administrativas por 1 ano, tempo estimado como suficiente para a estruturação dessas áreas na NTS, de modo que as atividades normais de faturamento, contas a pagar e a receber, gestão de caixa, processos de 
departamento pessoal, atividades jurídicas e regulatórias, dentre outras, continuariam a ser executadas pela equipe da empresa vendedora, sem prejuízos para o bom andamento da NTS, enquanto essa se estruturava. Um segundo conjunto de contratos estabelecia que a terceirização da operação e manutenção (O\&M) dos gasodutos seria mantida com o atual prestador de serviço por até 10 anos, podendo a NTS interromper esse contrato a partir do quarto ano. Esperava-se que nesse tempo a empresa fosse capaz de ganhar competência técnica necessária para gerir uma operação que era realizada há mais de 20 anos. Era claramente um desafio de acumulação de capital organizacional, uma vez que os ativos físicos já estavam instalados e em operação.

A NTS definiu logo em seus primeiros meses quais seriam a missão, visão e os valores da empresa. Essa atividade foi realizada com o primeiro grupo de empregados da empresa, quais eram seus diretores e alguns gerentes. Esse conjunto de estratégias fazia parte de um plano para os primeiros 100 dias da empresa e que tinha o objetivo de desenvolver em cada diretoria o seu plano de estruturação. $\mathrm{O}$ plano estratégico para os primeiros cinco anos estaria pautado no plano de negócios, desenhado quando o ativo foi comprado, e atenderia à expectativa dos investidores da empresa. Havia um claro desafio de estruturação de processos e de gestão de pessoas, atividades que seriam lideradas pela área de Gente e Gestão, mas executada por cada uma das cinco diretorias da empresa. A acumulação do capital humano e organizacional da NTS seria o desafio para a constituição dessa empresa e colocaria o RH no centro dessa estratégia, para a formação das competências da organização (Lado \& Wilson, 1994; Prahalad \& Hamel, 1990; Teece et al., 1997).

Nos primeiros dois anos, foram contratados cerca de 80 funcionários, que constituíam a equipe de processos administrativos da empresa e aqueles que iriam planejar a primarização das atividades de O\&M, sendo essa ação a mais complexa de todo o plano. A estratégia para a contratação inicial de funcionários para a área de Operações envolveu estudar onde estaria no Brasil o conhecimento de construção, manutenção e operação de gasodutos e quais conhecimentos correlatos poderiam ser identificados em outras indústrias. Identificou-se que a PUC-RJ possuía há 15 anos um curso de pós-graduação em Engenharia Dutoviária. Com isso, avaliando onde estariam os alunos formados nesse curso, foi identificado que a grande maioria deles eram funcionários da empresa estatal. Uma estratégia adotada, então, foi a busca de profissionais aposentados desta empresa, com conhecimento específico em operação de gasodutos, para compor uma parte do time de Operações, especialmente aqueles que iriam planejar a primarização das atividades de O\&M. A gestão de conhecimento deveria ser minuciosamente planejada para que esse conhecimento pudesse ser compartilhado e que novos funcionários fossem desenvolvidos (Prahalad \& Hamel, 1990). 
Outra atividade realizada foi $\mathrm{o}$ mapeamento de todos os processos administrativos e operacionais, considerando como eram feitos anteriormente- AS IS e como seriam realizados pela NTS - TO BE, já incorporando melhorias identificadas ao longo do trabalho. Esse mapeamento permitiu definir os processos que deveriam ser implementados, estabelecer um cronograma para essa implementação e dimensionar o tamanho do quadro de pessoal necessário para a empresa.

Na medida em que cada área contratava as pessoas e implementava os processos, poderia então finalizar o contrato daquela atividade com a empresa vendedora. Ao final de um ano, em abril de 2018, todos os processos administrativos estavam implantados na NTS e a equipe de Operações estava pronta para planejar a primarização das atividades de O\&M, o que foi feito por meio de um estudo aprofundado dos modelos de operação de gasodutos no mundo, buscando melhores práticas em empresas reconhecidas por sua excelência nessa área. Foram estudados os processos de duas empresas canadenses, e duas visitas técnicas em empresas de gasodutos foram realizadas; uma nos EUA, e outra na Holanda. A terceirização ou primarização das atividades de O\&M fazia parte da estratégia das empresas estudas e os dois modelos foram encontrados nas visitas técnicas. O tema é amplamente estudado em diversas indústrias, dentro e fora do Brasil (Drauz, 2014; Saraiva \& Mercês, 2013). No caso da NTS, a decisão por primarizar a atividade tinha o objetivo de criar competências essenciais numa indústria até então apenas estatal. (Prahalad \& Hammel, 1990).

Estabelecido e aprovado o plano de trabalho para a primarização, foi estabelecido um grupo de trabalho para essa implantação, constituído pelas áreas de Operações, Gente e Gestão, Tecnologia da Informação e Compras. A estimativa era a contratação de mais 135 profissionais para a internalização de todas as atividades, desenvolvimento de processos e sistemas de suporte para essa operação.

\section{Diagnóstico da situação-problema}

Ao ser declarada a Pandemia, a NTS decidiu instaurar um comitê de crise para avaliar as medidas que seriam adotadas na Cia. O comitê seria constituído pelo DiretorPresidente, Diretor de Operações, Diretor Financeiro, Diretora de Gente e Gestão, Gerente Jurídico, Gerente de Saúde, Segurança e Meio Ambiente (SSMA) e Gerente Comercial. O comitê teria também a participação eventual de um médico convidado, para poder orientar nas medidas de saúde adotadas mais à frente. Foram definidos os tópicos a serem acompanhados pelo comitê e os papéis e responsabilidades de cada um com objetivo de preservar todos os stakeholders da NTS, a saber, investidores, empregados e comunidades no entorno da NTS. $\mathrm{Na}$ figura 1, é possível verificar o organograma estabelecido para as ações do comitê.

Para a continuidade operacional e considerando que a atividade de suprimento de gás natural em toda a sua cadeia - produção, 
transporte e distribuição - foi declarada como essencial para o país (BRASIL, 2020), um plano para situações de emergências e crises era necessário. $\mathrm{O}$ plano de continuidade de negócios, mais conhecido como PCN, refere-se a um conjunto de estratégias e de planos de ação preventivos que garantem o pleno funcionamento dos serviços essenciais de uma empresa durante quaisquer tipos de falhas, até que a situação seja normalizada (Spremic et al., 2013). Embora o plano não considerasse um cenário de pandemia, ele era bastante adequado para avaliarmos os itens que seriam necessários para não paralisar as atividades.

Figura 1 - Organograma do comitê de crise para enfrentamento da pandemia Covid-19

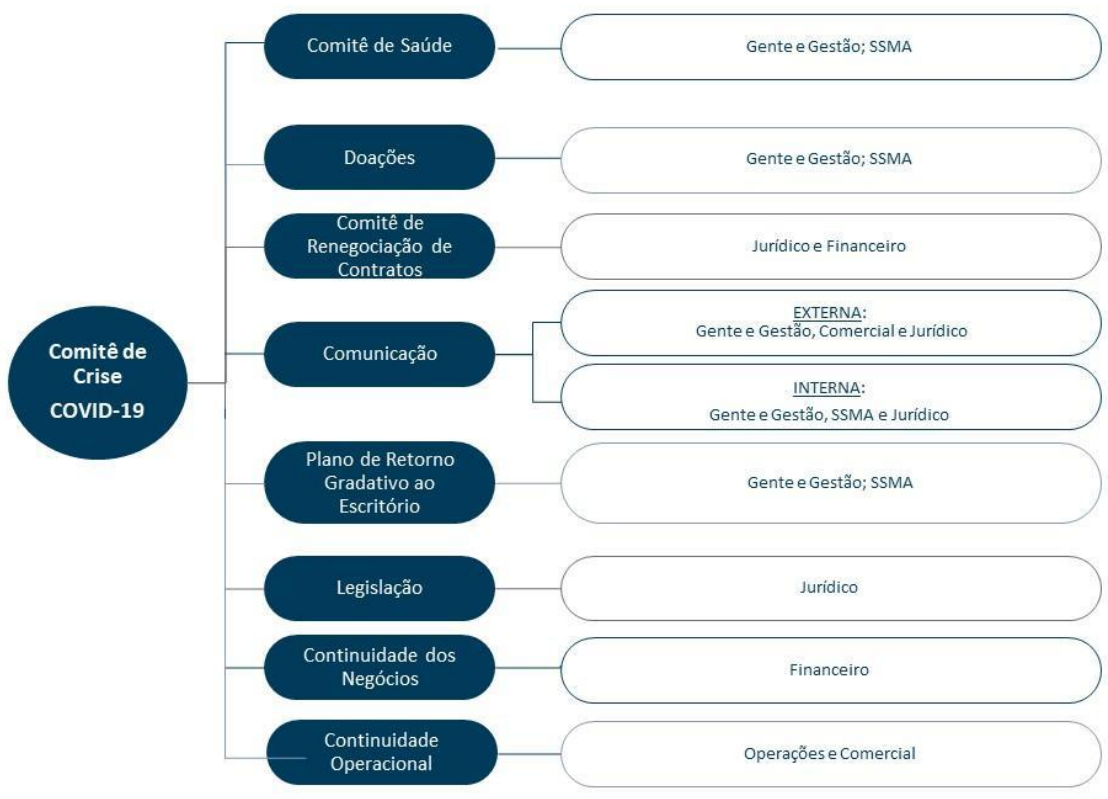

Fonte: fornecida pela empresa

A implantação do teletrabalho para $100 \%$ da equipe da NTS foi a principal medida para preservar a saúde dos empregados e garantir a continuidade de negócio nas atividades corporativas. Essa decisão não foi fácil. Inicialmente, havia a dúvida se essa não seria uma medida exagerada. A desinformação era grande e o vírus ainda desconhecido. A empresa ainda não possuía uma política de teletrabalho estabelecida. Sabia-se de vantagens e de desvantagens do modelo ( Filardi, Castro \& Zanini, 2020; Ikin, 2020) e isso precisaria ser considerado na estratégia de implantação. Os casos de Covid-19 no Brasil ainda pareciam ser poucos e especulava-se sobre a confiabilidade dos dados. Mas, após convidar um médico para participar de uma das reuniões do comitê de crise e avaliando o cenário apresentado, optouse pela implantação. Não seria algo complicado, dado que o plano de continuidade de negócio já havia preparado a empresa para isso desde 2018.

Todas as ferramentas necessárias, sob o ponto de vista de Tecnologia da Informação, já 
estavam disponíveis e as equipes treinadas para uso; quais seriam acesso remoto via VPN, servidores em nuvem, ferramentas de comunicação virtual etc. Contudo, de acordo com o plano, essas ferramentas estavam disponíveis para os empregados envolvidos em atividades críticas e para a implantação de teletrabalho para $100 \%$ da empresa, algumas medidas se fizeram necessárias para garantir que todos teriam as condições mínimas de trabalho em casa e a possibilidade de manter a produtividade como se estivessem no escritório. Essas medidas estão apresentadas na tabela 1.

A empresa considerou que poderia atuar também para preservar a saúde física e mental dos empregados durante o período de teletrabalho, especialmente considerando que a situação era nova e inesperada para todos, além de envolver outros membros da família. As medidas adotadas também foram descritas na $\mathrm{T}$ abela 1 e consideraram modelos já realizados em outras empresas e relatos de medidas exercidas em países com casos mais avançados (Fri, 2020; Koirala \& Acharya, 2020; Mckinsey, 2020).
Avaliando o seu papel em um momento tão crítico para a sociedade e as necessidades das comunidades no entorno do gasoduto, a empresa constatou que deveria atuar também na ajuda de combate aos efeitos da pandemia (Cheema-Fox et al., 2020; Christensen et al., 2016; Ng et al., 2019; Shan \& Tang, 2020). Para isso, foi aprovada junto com os investidores a doação de R \$ 6 milhões que seriam destinados a aparelhar hospitais com equipamentos necessários no tratamento da Covid-19, doações de EPIs para profissionais na linha de frente de atendimento aos infectados e cestas básicas para comunidades do entorno. Essa ação foi realizada prioritariamente nos municípios de menor IDH (Índice de Desenvolvimento Humano) ao longo da faixa de dutos, nos estados do Rio de Janeiro, Minas Gerais e São Paulo. Além disso, organizou-se uma frente de voluntariados com os funcionários para quem quisesse se engajar nas doações de cestas básicas, o que gerou a arrecadação de dois meses de atendimento para 100 famílias e mobilizou os empregados no combate aos efeitos da pandemia, gerando um forte sentimento de colaboração. 
Tabela 1 - Medidas adotadas pelo comitê de crise

\begin{tabular}{|c|c|}
\hline Implantação de teletrabalho & Preservar a saúde dos empregados \\
\hline $\begin{array}{l}\text { Conversão dos contratos de trabalho de todos os } \\
\text { funcionários para o regime de teletrabalho }\end{array}$ & $\begin{array}{l}\text { Campanha de vacinação contra H1N1 para } 100 \% \text { dos } \\
\text { empregados e seus dependentes em ambulatório } \\
\text { exclusivo, com adesão de } 80 \% \text { do público }\end{array}$ \\
\hline $\begin{array}{l}\text { Distribuição de computadores portáteis para os que } \\
\text { não tinham esse equipamento e liberação de acesso } \\
\text { VPN }\end{array}$ & $\begin{array}{l}\text { Monitoramento do estado de saúde física e mental dos } \\
\text { empregados e do perfil daqueles que iriam compor o } \\
\text { grupo de risco (por questionário semanal preenchido } \\
\text { via aplicativo) }\end{array}$ \\
\hline $\begin{array}{l}\text { Permissão para retirada de itens de ergonomia do } \\
\text { escritório: cadeiras, apoio para os pés, monitores, } \\
\text { teclados, mouse e até mesmo aluguel de mobiliário, } \\
\text { como escrivaninha para os que não tinham mesa ou } \\
\text { algum outro móvel onde pudessem trabalhar; }\end{array}$ & $\begin{array}{l}\text { Análise de dados por especialistas que atuavam } \\
\text { quando o empregado sinalizava apresentar sintomas } \\
\text { de Covid-19 ou propensão a desenvolvimento de } \\
\text { depressão ou ansiedade em função do isolamento } \\
\text { social. }\end{array}$ \\
\hline $\begin{array}{l}\text { Fornecimento de internet móvel ou reembolso de } \\
\text { upgrade de banda larga para os que não tinham esse } \\
\text { tipo de serviço disponível em suas casas; }\end{array}$ & $\begin{array}{l}\text { Oferta de suporte psicológico e de assistência social } \\
\text { para os empregados e seus familiares durante o } \\
\text { período de pandemia }\end{array}$ \\
\hline $\begin{array}{l}\text { Ampliação das licenças de uso das ferramentas de } \\
\text { assinatura eletrônica de documentos, antes disponíveis } \\
\text { apenas para contratos }\end{array}$ & $\begin{array}{l}\text { Aulas de ioga e treinamento funcional no início e fim } \\
\text { da jornada. O objetivo também era estimular que não } \\
\text { houvesse excesso de jornada de trabalho, além de } \\
\text { preservar a saúde física e mental }\end{array}$ \\
\hline $\begin{array}{l}\text { Ação de desenvolvimento para líderes aprenderem a } \\
\text { gerir equipes à distância }\end{array}$ & $\begin{array}{l}\text { Oferta de palestras diversas com especialistas que } \\
\text { pudessem auxiliar os empregados e tirar dúvidas: } \\
\text { Covid-19 e seus impactos; saúde mental, paternidade } \\
\text { e maternidade em tempos de teletrabalho etc. }\end{array}$ \\
\hline $\begin{array}{l}\text { Manutenção dos rituais de comunicação do CEO e } \\
\text { Diretores com todos os empregados, alterando apenas } \\
\text { para o modelo de videoconferência }\end{array}$ & $\begin{array}{l}\text { Oferta de serviços de telemedicina e exames de Covid- } \\
19 \text { com coleta domiciliar }\end{array}$ \\
\hline
\end{tabular}

Fonte: Elaborado pela autora.

Estabelecidas as ações que mitigariam riscos à saúde dos empregados e de seus familiares, à continuidade operacional e à preservação do caixa da companhia, seria necessário revisitar o planejamento estratégico e, especialmente, o projeto de internalização das atividades de O\&M. A companhia estava prestes a contratar a equipe de operação dos gasodutos e iniciar um programa de 12 meses de treinamento para esses profissionais, em função da escassez dessa mão de obra treinada no mercado de trabalho brasileiro. Todo o treinamento estava desenhado para ser executado de forma presencial, mas a incerteza quanto ao término da pandemia não permitia saber se seria melhor aguardar o momento em que se poderia realizar o treinamento presencialmente. Essa decisão poderia atrasar o cronograma de implantação do projeto, previsto para abril de 2021.

\section{Intervenção proposta}

O grupo responsável pelo projeto de internalização das atividades de O\&M avaliou o cenário que se apresentava em abril de 2020 no Brasil, diante da pandemia da Covid-19. Naquele momento, a curva de contaminação estava crescendo e a recomendação era o isolamento social. Várias cidades começavam a adotar o fechamento de atividades consideradas não essenciais e a praticar o chamado lockdown. 
Não havia nenhuma previsão de retorno de atividades com aglomeração de pessoas em locais fechados como, por exemplo, os treinamentos presenciais.

Das atividades previstas no cronograma do projeto, a contratação e treinamento dos empregados eram as mais impactadas pelo momento de isolamento social. Todas as demais atividades poderiam ser realizadas, mesmo no regime de teletrabalho, ainda que com certo grau de dificuldade. Foi feita, também, uma avaliação da cadeia de suprimentos, considerando fornecedores de equipamentos e serviços nessa etapa do cronograma e nenhum dos fornecedores apresentou qualquer impedimento para a entrega de produtos e serviços contratados. Dessa forma, o time considerou que todas as atividades que envolviam o grupo de funcionários para a operação de gasodutos deveriam se adaptar para serem executadas no mesmo regime de teletrabalho que os demais empregados da Cia. (Koirala \& Acharya, 2020; Vardarler, 2016).

Para executar o treinamento, que antes estava previsto para ser presencial, foi necessária a adaptação para o modelo de ensino à distância. $\mathrm{O}$ parceiro contratado para gerir e executar a trilha de treinamento desenhada tinha competência para executá-lo à distância, mas precisaria fazer alterações no programa, reforçar seu sistema de aula on-line, contratar mão de obra de suporte para os instrutores e treiná-los para o uso da nova tecnologia. A alteração do modelo de treinamento ficou planejada para ser realizada em dois meses e, assim, as contratações que seriam feitas em abril de 2021 foram adiadas para junho do mesmo ano.

Os gestores já estavam acostumados a executar entrevistas on-line, especialmente para candidatos que estavam fora do Rio de Janeiro. $\mathrm{O}$ fornecedor que apoiava no processo de recrutamento e seleção (R\&S) também já dispunha de ferramentas para ter seus funcionários em teletrabalho. Dessa forma, a etapa de $R \& S$ não foi interrompida em nenhum momento. Apenas foi adotado o modelo 100\% on-line para o processo seletivo.

Para manter os candidatos interessados nas vagas e gerar conexão com a empresa, investiu-se em intensificar as publicações e comunicações via rede social LinkedIn. A empresa passou a divulgar as ações que estava fazendo para engajar seus empregados durante o período de pandemia, bem como as medidas que vinha tomando para preservar os empregados, atender os seus clientes e suportar as comunidades no seu entorno. Esse plano de comunicação tinha o objetivo de aumentar o engajamento com a marca empregadora, conhecida como Employer Value Proposition (EVP) (Ng et al., 2019; Shan \& Tang, 2020), e assim atrair talentos para a empresa, que estava com um grande desafio de contratação de funcionários em meio à pandemia.

Para o processo de admissão dos empregados, a empresa adotou a carteira de trabalho digital, já disponibilizada pelo Governo Federal brasileiro. Além disso, ampliou o uso do sistema de assinatura digital 
de documentos. Dessa forma, foi possível realizar todo processo admissional de forma remota, garantindo o recebimento e envio de documentos assinados, e toda regularidade que é necessária para cumprir as obrigações trabalhistas.

\section{Resultados obtidos}

Desde o início da pandemia de Covid19, a NTS vem operando remotamente, com $100 \%$ dos empregados corporativos em teletrabalho. $\mathrm{E}$ as atividades operacionais terceirizadas operando em regime de contingência. Nenhuma interrupção no fornecimento do serviço de transporte de gás natural foi registrada no período. Observou-se redução nos volumes transportados, especialmente nos meses de abril e maio, consoante demonstrado no Figura 2. A queda do volume se deu pela redução da demanda industrial. Esses resultados em nenhum momento foram afetados pelo serviço de transporte, que permaneceu disponível durante todo o período.

Figura 2 - Volume de gás transportado para distribuidoras e termoelétricas

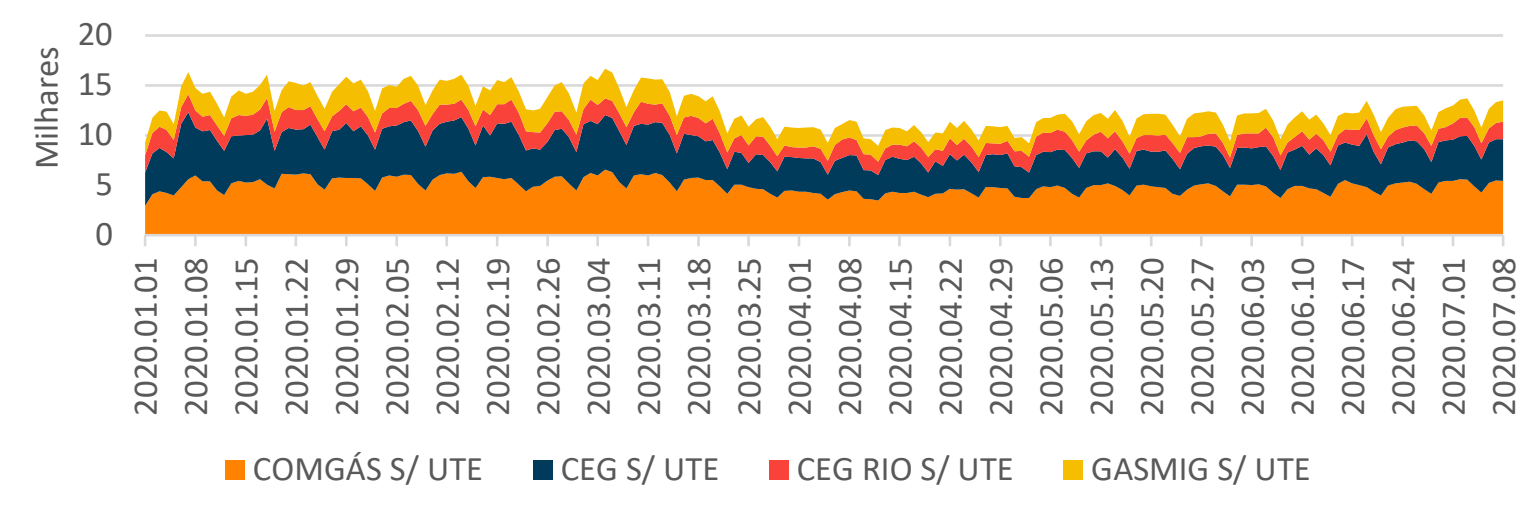

Fonte: Fornecido pela empresa.

Sobre a preservação da saúde dos empregados da NTS e de seus familiares, foram registrados 4 casos de contaminação dentre os 175 funcionários da Cia. entre março e junho de 2020, bem como 4 casos de contaminação dentre 149 dependentes diretos. Todos os casos apresentaram sintomas leves e, em função dos sintomas, foram submetidos a testes, demonstrando resultados positivos. Nenhum funcionário ou dependente precisou ser internado para tratamento e nenhum óbito foi registrado.
Em relação ao engajamento com a marca empregadora (EVP), foi possível observar uma média de 226 novos seguidores por semana no período de 16 de março a 16 de junho (Figura 3), acumulando um total de 14703 seguidores. A taxa de engajamento com a marca no LinkedIn foi de $7.47 \%$ A média de engajamento de empresas do mesmo segmento nessa rede social é de 4,97\%, conforme dados da página da rede social LinkedIn. 
Figura 3 - Quantidade de novos seguidores na página da NTS na rede social LinkedIn

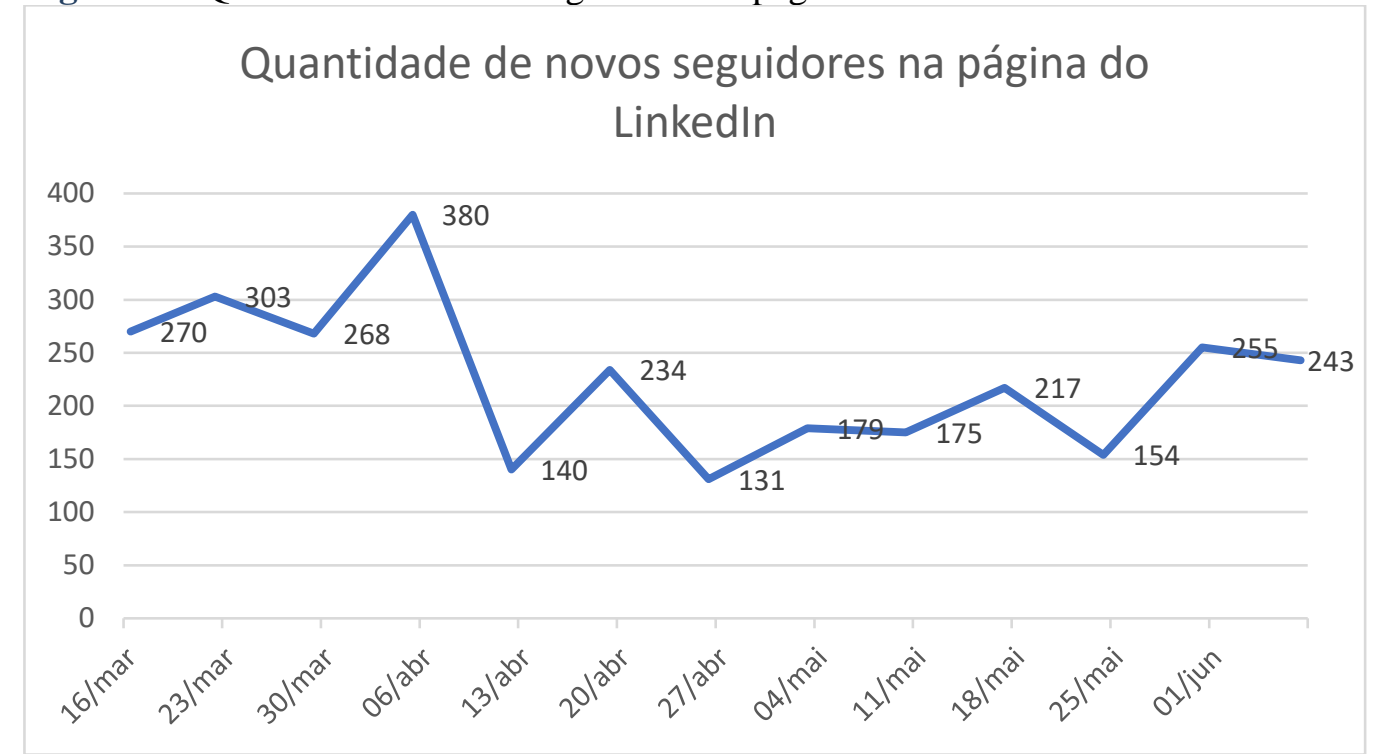

Fonte: Elaborado pela autora, 2021.

Apesar de adiar em dois meses o início das contratações das equipes para o projeto de internalização das atividades operacionais, em função da necessidade de adaptação dos treinamentos previstos para serem realizados presencialmente para um modelo $100 \%$ on-line, a empresa conseguiu concluir $100 \%$ das contratações previstas no cronograma para a internalização das atividades operacionais. Portanto, iniciou em junho de 2020 o treinamento on-line dos técnicos de gasodutos e dos técnicos do centro de controle operacional. Os treinamentos teóricos estão previstos para acontecer até dezembro de 2020. A partir de janeiro de 2021, o treinamento prático será iniciado e espera-se poder realizá-lo presencialmente. De qualquer forma, a empresa vem desenvolvendo simuladores que poderão ser utilizados para treinamentos à distância, se for necessário.
Durante esse período de pandemia, duas pesquisas foram realizadas com os empregados, a fim de entender como estava a adaptação deles ao teletrabalho e como percebiam o nível de produtividade. Na Figura 4, é possível observar que, após dois meses de teletrabalho, os empregados mudaram a sua percepção sobre estar $100 \%$ nessa condição, de forma compulsória. Enquanto no começo da pandemia a maioria preferia estar em teletrabalho, no segundo mês eles já acreditavam que um modelo híbrido seria mais adequado, podendo escolher quando estar no escritório e quando estar em teletrabalho. Essa parece ser a medida que a maioria das pessoas prefere, a saber, não ter um trabalho 100\% remoto, mas poder ter a flexibilidade de usar dessa prerrogativa para melhorar a qualidade de vida e alcançar maior equilíbrio entre vida pessoal e profissional. 
Figura 4 - Percepção dos empregados sobre o regime de teletrabalho

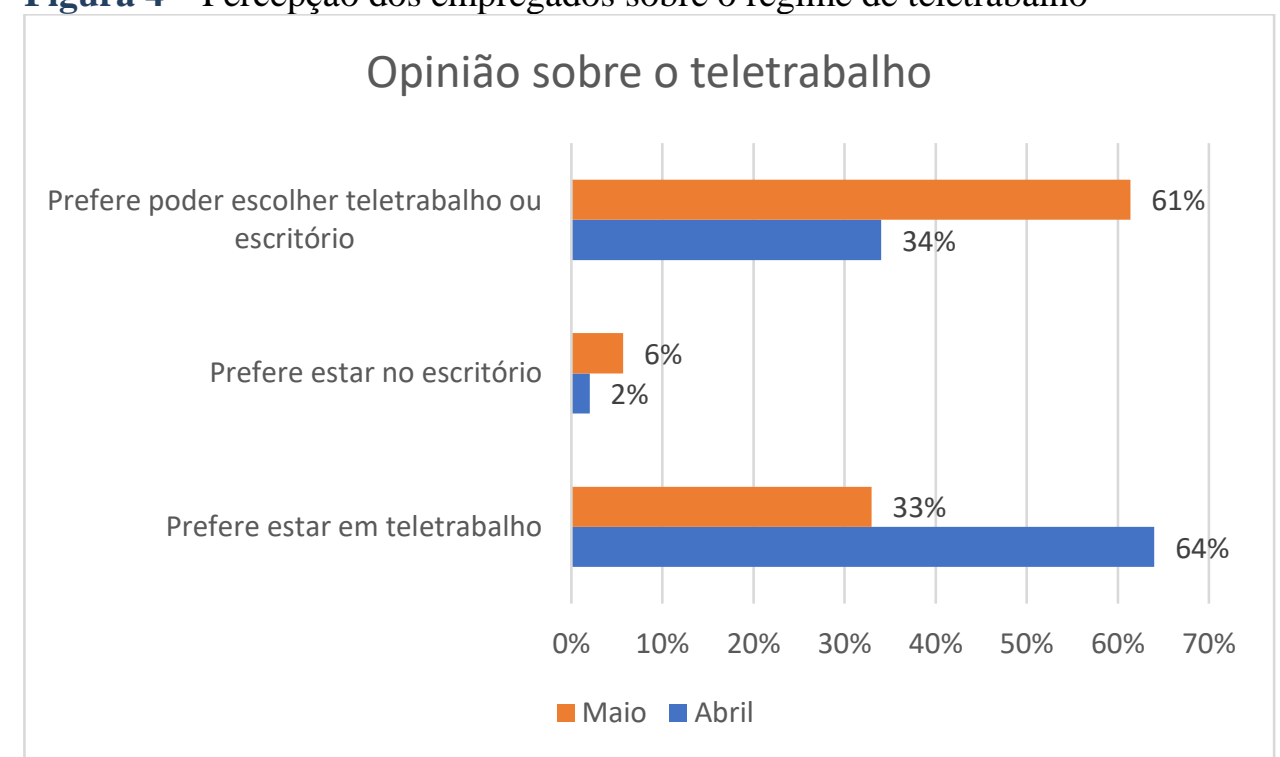

Fonte: Elaborado pela autora a partir de pesquisa feita pela empresa.

Outro item avaliado foi o quanto os empregados estavam adaptados ao trabalho remoto, haja vista que era a primeira vez que a empresa havia implementado esse regime. De acordo com a Figura 5, foi observada uma redução de dois pontos percentuais na quantidade de empregados que se sentiam plenamente adaptados ao teletrabalho, mas preservando ainda a maioria dos respondentes nesse status. É importante ressaltar que nesse período algumas pessoas foram contratadas e entraram na empresa já no regime de teletrabalho, sem passar por nenhuma experiência presencial com seus pares e gestores. Entende-se que esse possa ser um fator, apesar de a redução na adaptação ainda ter sido bem pouco expressiva. A empresa procurou entender os motivos da falta de adaptação ao teletrabalho e os maiores pontos alegados pelos empregados eram a falta de infraestrutura similar à do escritório, especialmente internet, e também a necessidade de realizar as atividades domésticas e dividir a atenção entre o trabalho e o cuidado com os filhos que estavam em casa, muitos com atividades escolares também remotas. 
Figura 5 - Adaptabilidade ao teletrabalho

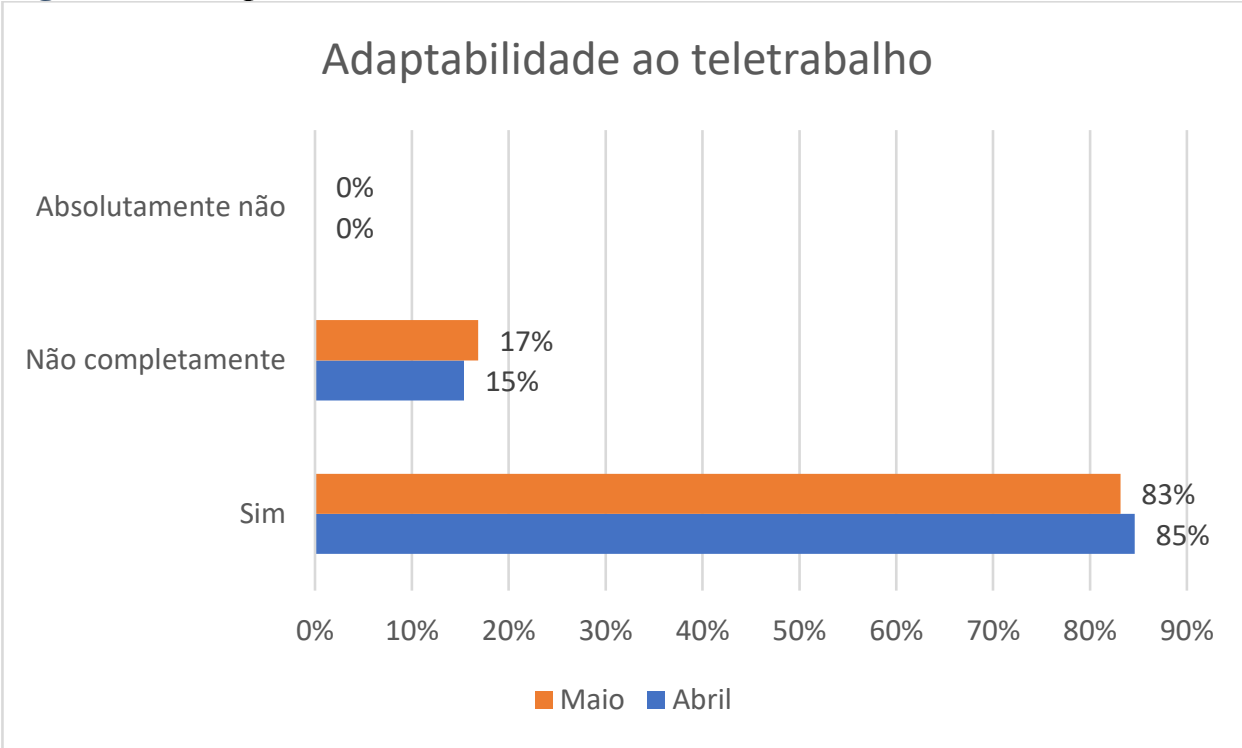

Fonte: Elaborado pela autora a partir de pesquisa feita pela empresa.

E, por fim, a empresa quis entender como os funcionários percebiam a sua produtividade nesse período de teletrabalho. $\mathrm{Na}$ Figura 6, é possível observar que entre abril e maio houve um aumento de 4 pontos percentuais dentre os que percebiam maior produtividade, combinada com a redução dos mesmos 4 pontos percentuais dentre os que percebiam menor produtividade. Entende-se que as pessoas se adaptaram à condição de teletrabalho junto com as atividades familiares e conseguiram melhorar a sua produtividade no período.

Figura 6 - Percepção dos empregados sobre o seu rendimento no trabalho

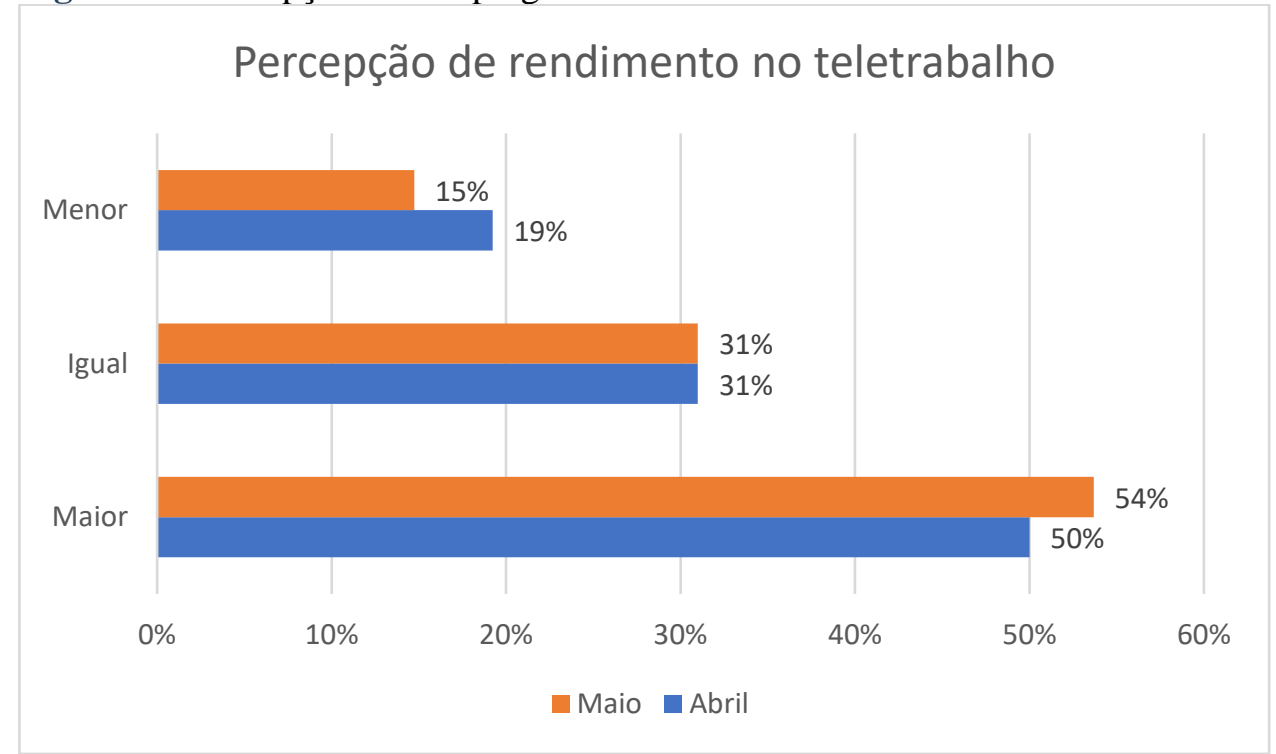

Fonte: Elaborado pela autora a partir de pesquisa realizada pela empresa 


\section{Contribuição tecnológico-social}

Esse relato teve como objetivo apresentar como o capital humano atuou e foi impactado pelas medidas adotadas por uma empresa durante a crise da pandemia de Covid19 no Brasil, de que forma os executivos se estruturaram para atuar e os resultados das medidas que tomaram, mesmo em um cenário complexo e incerto.

Os resultados preliminares demonstram que, ao concentrar esforços em preservar a saúde dos empregados e de seus familiares, a continuidade operacional e a preservação do caixa da companhia, a empresa pôde adotar medidas que tinham em seu caráter um cuidado com as partes relacionadas com a empresa, a saber, empregados, acionistas e comunidades no entorno do gasoduto.

Em pouco tempo, foi possível concluir que a crise tinha muito mais um impacto nas pessoas do que no negócio para a empresa em questão, e, assim, o papel do capital humano, que já era primordial para a tomada de decisão, tomou maior relevância, pois o cuidado com as pessoas e com a manutenção do seu engajamento manteria as atividades da empresa e permitiria transformar uma situação adversa em uma oportunidade.

A empresa conseguiu manter suas operações sem interrupção durante o período, o que é bastante relevante, uma vez que é uma empresa regulada e tem sua atividade considerada como serviço essencial. Foi possível também seguir com o planejamento estratégico estabelecido, sem necessidade de revisão das metas anuais e com manutenção das atividades previstas para o ano.

Durante a crise, foi possível observar um aumento no engajamento dos empregados, que se esforçaram para manter as atividades sendo executadas, mesmo em uma situação adversa, estabelecendo assim uma relação de maior confiança e de alinhamento entre gestores e empregados e também com a empresa e os valores que apregoa. No mais, observou-se ainda o aumento da percepção da sua marca empregadora nas redes sociais, ganhando uma reputação valiosa em um período de crise como o atual e atraindo talentos para o seu quadro de empregados.

Estar preparado para lidar com crises, treinando cenários, tendo uma governança estabelecida e prontidão para dar resposta, foi um dos aprendizados obtidos pela empresa, que continua reforçando seu programa de gestão de crise. Outro ponto ressaltado é que a gestão de pessoas nesse momento é tão fundamental quanto a gestão da reputação e dos ativos. Pensar no impacto da crise sobre a motivação e engajamento das pessoas e implementar ações que demonstrem cuidado, foram essenciais no caso em questão, para evitar qualquer interrupção das atividades em curso e das ações previstas no planejamento estratégico da empresa.

É importante ressaltar que, no momento em que esse relato técnico está sendo escrito, a pandemia ainda não terminou. Em suma, a avaliação de sucesso ao lidar com uma crise geralmente é feita considerando erros e acertos 
das organizações, quando em situações como essa (Christensen et al., 2016; Coombs, 2000; Myer et al., 2007). Poder avaliar durante a crise erros e acertos, corrigir rumos e compartilhar esses aprendizados é de grande valor para as organizações (Caldeira \& Godoy, 2011; Coombs, 2000). Espera-se que esse relato produza esse efeito ainda nesse momento da pandemia atual e para situações de crises futuras.

\section{Referências}

't Hart, P., Rosenthal, U., \& Kouzmin, A. (1993). Crisis decision making: The centralization thesis revisited. Administration \& Society, 25(1), 12-45.

Albuquerque, R. A.; Koskinen, Y.;Yang, S.; \& Zhang, C. (2020). Love in the Time of COVID-19: The Resiliency of Environmental and Social Stocks. SSRN, 32.

Agência Nacional de Petróleo, Gás Natural e Biocombustíveis (2019). Anuário Estatístico 2019, 1-264. Recuperado em 30 de abril de http/anp.gov.br/publicacoes/anuarioestatistico/5237-anuario-estatistico-2019

Boin, A. (2019). The Transboundary Crisis: Why we are unprepared and the road ahead. Journal of Contingencies and Crisis Management, 27(1).

Caldeira, adilson, \& Godoy, A. S. (2011). Barreiras e Incentivos à Aprendizagem Organizacional: um estudo de caso. Revista de Gestão, 18(4), 513-530.

Cheema-Fox, A., LaPerla, B. R., Serafeim, G., $\&$ Wang, H. (2020). Corporate Resilience and Response During COVID-19. Harvard Businesss Scholl, 20-108.

Christensen, T., Andreas Danielsen, O., LÆgreid, P., \& Rykkja, L. H. (2016). Comparing coordination structures for crisis management in six countries. Public Administration, 94(2).

Christensen, T., Lægreid, P., \& Rykkja, L. H. (2016). Organizing for Crisis Management: Building Governance Capacity and Legitimacy. Public Administration Review, 76(6), 887-897.

Coombs, W. T. B. T.-R. of B. (2000). Designing Post-Crisis Messages: Lessons for Crisis Response Strategies, 21(3), 37.

Coulson-Thomas, C. (2019). Board Leadership, Crisis Governance and Governance in Crisis. Effective Executive, 22(3), 42-58. Recuperado em 30 de abril de 2020 de http://elib.tcd.ie/login?url=https://search.proq uest.com/docview/2311516840? accountid=1 4404

Decreto $\mathrm{N}^{\circ} 10.329$, de 28 de abril de 2020. Amplia a lista de atividades essenciais. Diário Oficial da União. Brasília. DF.

Drauz, R. (2014) Re-insourcing as a manufacturing-strategic option during a crisis - Cases from the automobile industry. Journal of Business Research, v. 67, n. 3, p. 346-353.

Edmans, A. (2011). Does the Stock Market Value Intangibles? Employee Satisfaction and Equity Prices: 9 / 10. Journal of Financial Economics, 101, 621-640.

Filardi, F., Castro, R. M. P. de, \& Zanini, M. T. F. (2020). Vantagens e desvantagens do teletrabalho na administração pública: análise das experiências do Serpro e da Receita Federal. Cadernos EBAPE.BR, 18(1), 28-46.

Fri, A. G. (2020). How is Marel, a global manufacturing company headquartered in Iceland, dealing with the COVID-19 crisis? Master of Project Management, 1-21. Recuperado em 30 de abril de 2020 de https://skemman.is/bitstream/1946/36370/1/ The \%20COVID-19\%20crisis\%20\%20Case\%20study.pdf.

Hermann, C. F. (1972). International crises; 
insights from behavioral research. (Free Press, Ed.).

Ikin, H. (2020). Perks and pitfalls of working from home: Will COVID-19 change the future of work? Australian Psychological Society. Recuperado em 30 de abril de 2020 de https://www.psychology.org.aulformembers/publications/inpsych/2020/JuneJuly-Issue-3/Perks-and-pitfalls-of-workingfrom-home-(1)

Kim, Y., \& Lim, H. (Dana). (2020). Activating constructive employee behavioural responses in a crisis: Examining the effects of pre-crisis reputation and crisis communication strategies on employee voice behaviours. Journal of Contingencies and Crisis Management, 28(2), 141-157.

Koirala, J., \& Acharya, S. (2020). Dimensions of Human Resource Management Evolved with the Outbreak of COVID-19. SSRN Electronic Journal, 1-8.

Lado, A. A., \& Wilson, M. C. (1994). Human resource systems and sustained competitive advantage: A competency-base ... Academy of Management Review, 19, 699-727.

Lockwood, N. R. (2005). Crisis Management in Today's Business Environment: HR's Strategic Role. The Society for Human Resource Management (SHRM), 1-10. Retrieved from https://www.shrm.org/hrtoday/news/hrmagazine/documents/1205rquartpdf.pdf

Mckinsey. (2020). The path to the next normal, (May), 1-188. Recuperado em 30 de abril de 2020 de https://www.mckinsey.com/industries/health care-systems-and-services/ourinsights/beyond-coronavirus-the-path-to-thenext-normal

Myer, R. A.; Conte, C., \& Peterson, S. E. (2007). Human impact issues for crisis management in organizations. Disaster Prevention and Management: $A n$ International Journal, 16(5), 761-770.

Nathan, M. B. T.-R. of B. (2000). The
Paradoxical Nature of Crisis, 21(3), 12.

Ng, T. W. H., Yam, K. C., \& Aguinis, H. (2019). Employee perceptions of corporate social responsibility: Effects on pride, embeddedness, and turnover. Personnel Psychology, 72 (1). DOI:

https://doi.org/10.1111/peps.12294

Penrose, E. (1959). Theory of the Growth of the Firm (1a. Ed.). São Paulo: Editora Unicamp.

Prahalad, C. K., \& Hamel, G. (1990, May). The Core Competence of the Corporation. Harvard Business Review, 79-91.

Robinson, C. (2005). Preparing for the Unexpected: Teamwork for Troubled Times. Journal for Quality and Participation, 28(1).

Rojo, C. A., \& Walter, S. A. (2014). Resumo relato técnico: roteiro para elaboração. Revista Competitividade e Sustentabilidade, 1(N. 1), 1-8.

Santos, R. (2000). Plano Decenal de Expansão de Energia 2029, 1-393. Recuperado em 30 de abril de 2020 de https://www.epe.gov.br/sites-pt/publicacoesdadosabertos/publicacoes/Documents/PDE\%2020 29.pdf

Saraiva, L.A.S \& Mercês, R.E. (2013) Terceirização na Gestão da Manutenção: Estudo de Caso de uma Mineradora. RAU, V. 11, n. 1

Schmidt, F.; \& Mello, J. (2020). A crise de Covid-19: impactos da pandemia e recomendações de políticas públicas, 1-112. Recuperado em 30 de abril de 2020 de https://www.ipea.gov.br/portal/images/storie s/PDFs/boletim_internacional/200505_BAPI \%2022\%20_COVID\%2019\%20_\%20COMP LETO_WEB.pdf

Shan, C.; \& Tang, D. Y. (2020). The Value of Employee Satisfaction in Disastrous Times: Evidence from COVID-19. SSRN, 21(1), 19.

Spremic, M., Bajgorić, N., \& Turulja, L. 
(2013). Implementation of it governance standards and business continuity management in transition economies: The case of banking sector in Croatia and BosniaHerzegovina. Ekonomska Istrazivanja, 26(1), 183-202.

Teece, D. J., Pisano, G., \& Shuen, A. (1997). D ynamic capabilities and strategic management. Strategic Management Journal, 187, 509-533.

Vardarlier, P. (2016). Strategic Approach to Human Resources Management During Crisis. Procedia - Social and Behavioral Sciences, 235, 463-472.
Wright, P M, Dunford, B. B., \& Snell, S. A. (2001). Human resources and the resource based view of the firm. Journal of Management, 27(6), 701-721.

Wright, Patrick M, McMahan, G. C., \& Mcwilliams, A. (1994). Human resources and sustained competitive advantage : A resource-based perspective Center for Effective. International Journal of Human Resource Management, 5, 301-326.

Yin, R. K. (2015) Estudo de Caso: Planejamento e Métodos. $5^{\mathrm{a}}$ Ed. Bookman. 